\title{
Choosing not to know: accounts of non-engagement with pre- symptomatic testing for Machado-Joseph disease
}

\author{
Álvaro Mendes $\mathbb{( i}^{1} \cdot$ Milena Paneque $\mathbb{I}^{1} \cdot$ Angus Clarke $\mathbb{I}^{2} \cdot$ Jorge Sequeiros $\mathbb{(}^{1,3}$
}

Received: 11 April 2018 / Revised: 9 November 2018 / Accepted: 22 November 2018 / Published online: 20 December 2018

(c) European Society of Human Genetics 2018

\begin{abstract}
This paper reports accounts from people at-risk for, or affected by, Machado-Joseph disease, and their family members, about their decisions not to seek pre-symptomatic testing, therefore remaining (for the time) uninformed about their genetic status. We draw on individual and family semi-structured interviews with participants recruited through a national patient's association $(n=25)$. Qualitative thematic analysis revealed three main categories of accounts: (1) justifying the decision "not to know", because either no clinical benefit was expected or predictive knowledge was anticipated as psychologically burdensome; (2) prioritizing everyday life, maintaining hope and the goal of living a valid life; and (3) the wish to know: ambivalence and conflict within the family. Findings suggest the value of genetic information is often questioned when no effective treatment or cure is available; and that people have different tolerance thresholds for predictive information, and this impacts individuals within the family differently. We discuss this in the context of the making of "responsible" decisions, and of the tensions that may arise within families between the best interests or wishes of a person and those of other family members. We hope this will clarify the reasoning of those who opt for non-engagement with medical genetic services and, more specifically, pre-symptomatic testing. Further, we hope it will be relevant for the provision of genetic counselling and psychosocial support to such families.
\end{abstract}

\section{Introduction}

Decisions to undergo pre-symptomatic testing (PST) for highly penetrant, late-onset neurological diseases (LONDs) are commonly permeated by great psychosocial complexity [1]. Genetic counselling and PST are standard procedures offered to individuals at-risk for LONDs, in accordance with guidelines that might be applied in different contexts and for a range of diseases [2]. For some, PST can provide helpful information, namely clinical surveillance for early signs of the disease and early treatment of complications;

Álvaro Mendes

alvaro.mendes@ibmc.up.pt

1 UnIGENe and CGPP - Centre for Predictive and Preventive Genetics, IBMC - Institute for Molecular and Cell Biology, i3S Instituto de Investigação e Inovação em Saúde, Universidade do Porto, Porto, Portugal

2 School of Medicine, Institute of Medical Genetics, Cardiff University, Wales, UK

3 ICBAS - Instituto de Ciências Biomédicas Abel Salazar, Universidade do Porto, Porto, Portugal however, for severely incapacitating LONDs, such as Machado-Joseph disease (MJD) and when no medical intervention is currently available, PST provides information without leading to any direct clinical benefit.

MJD (also known as spinocerebellar ataxia type 3, SCA3) is a dominantly inherited, multisystem degenerative disorder (average age-of-onset: 40.5 years); symptoms generally include progressive motor difficulties, incoordination of gait, speech and fine movements of the hands, involuntary eye movements, and, later on, complete loss of autonomy in daily living [3]. MJD is the most common SCA worldwide; its highest frequency is described in Brazil, Portugal, and China [4]. In Portugal, MJD has an overall prevalence of 3.1:100,000, but some clusters have higher rates (835.2 in Flores and 27.1 in São Miguel, Azorean islands; and 14.4:100,000 in central areas of the mainland, especially along the Tagus valley) [5].

Research indicates that relatively few individuals at-risk for LONDs request PST. For example, in Brazil, only $9 \%$ of the estimated population at 50\% risk for MJD completed PST [6]; uptake of PST for Huntington disease (HD) in the UK was estimated as $17.4 \%$ [7], while in Cuba the uptake of PST for SCA2 was estimated to be $24.9 \%$ [8]. While the 
psychological and social understanding of the experiences and consequences of PST for MJD, is well documented [914], far less is known about those who decide not to undertake PST. Most psychosocial studies have been conducted in the context of PST, and thus recruit self-selected individuals already attending genetics clinics; it is far more difficult to access a representative, unselected population. One factor that may make those at risk reluctant to take part in research and to contact clinical genetics services is their wish (and right) not to know their genetic status or not to be reminded of their risks too often. Much previous research has focused on at-risk subjects who request PST but then decide not to proceed [15, 16]; or on what is reported second-hand by those who proceed with testing, about their relatives who chose not to know.

To our knowledge, only one study has addressed those who chose not to undertake PST for MJD: an ethnographic study reported concerns among Brazilian MJD families with the emotional impact of a positive test result, including that it could hasten evolution of symptoms, and prevent attaining normative life goals [17]. Other research reported how individuals who made no attempts to seek PST for HD may be judged negatively by relatives and are often asked to justify their decision [18]; this creates tension in family relationships, as others regard it as a moral imperative to do so. Comparable findings have been reported in a family with limb-girdle muscular distrophy [19] and a kinship with Lynch syndrome (LS) [20]. A recent study described 'decliners' of predictive testing for LS (which has the possibility of medical follow-up and preventive measures) as ranging from being uninformed to declining testing at all, not perceiving benefits and fearing negative consequences [21]. Taken together, these findings suggest that 'decliners' or 'non-requesters' have different positionings towards genetic information and make their decisions within a different logic and morality, when compared with each other or with those who have engaged with genetic testing. Thus, circumstances around nonengagement with PST for MJD may not have been adequately reported so far. This paper aims to contribute to this knowledge, by reporting accounts from persons at-risk of, or affected by, MJD and their family members, about their (current or past) decisions of not seeking PST, or their opinions concerning relatives who decided not to undertake PST.

\section{Methods}

This exploratory, qualitative study was drawn from a larger empirical study examining processes of communication of information about genetic risks in families affected by LONDs, including familial amyloid polyneuropathy TTR
Val30Met, HD and MJD [22-24]. We present here the subcorpus of data focusing on decisions of non-engagement with PST, a relevant theme that emerged during that analysis, drawing on data from families with MJD (the majority in that study).

\section{Recruitment}

Following approval by the IBMC Human Ethics Committee, participants were recruited through the national patients' association for hereditary ataxias. Inclusion criteria involved persons potentially competent to give consent, either affected or at-risk for MJD, or their family members. A leaflet with information about the study and its aims, inviting people for an interview, was circulated in newsletters and website of the association and in social media, asking those potentially willing to participate to contact the researcher. The patients' association also made the study known at members' meetings; those agreeing to participate authorized their contact information to be sent to the main researcher, who then contacted them. Snowball sampling [25] was also adopted by asking participants whether they knew other persons or families that might be interested to participate.

\section{Participants}

Data pertaining to non-engagement with PST involved a sub-corpus of 12 interviews, out of 32; of those, 8 interviews involved participants from MJD families, 6 of which included multiple family members (i.e., a joint interview with relatives and non-biological family members). Overall, this study comprised 25 participants (subsequent contact with two potential participants failed), all of whiteEuropean ethnic background (cf. Table 1 for sociodemographic and disease-related information).

\section{Data collection}

Interviews were conducted between April 2014 and June 2017, at the participant's home (5), in a primary health center (2), or in a public space (1), as chosen by them. All were conducted by ÁM, after written consent had been obtained. Interviews were audiotaped with the participants' consent, transcribed, and translated into English. Each lasted $\sim 1 \mathrm{~h}$. Social, demographic, and disease-related data were collected, followed by an open question about experiences of living with, or at risk of, the disease. Interviews centered on the value of genetic information, motivations, and engagement with PST, and experiences of talking to relatives about test results or genetic risks more broadly. The focus was on what issues they found important and how they expressed and elaborated their arguments. Case 
Table 1 Social, demographic and disease-related information

\begin{tabular}{ll}
\hline Information & $n$ (total: 25) \\
\hline Age & $11-68$ (mean: 42.4) \\
$<18$ & 2 \\
$18-25$ & 2 \\
$26-35$ & 6 \\
$36-45$ & 2 \\
$46-55$ & 8 \\
$>55$ & 5 \\
Gender & 14 men, 11 women \\
Education & 8 (inc. 1 attending) \\
$4-6$ years & 15 (incl. 1 attending) \\
9-12 years & 2 (incl. 1 attending) \\
University degree & 16 (14 married) \\
Civil status & 2 \\
In a relationship & 2 \\
Divorced & 5 \\
Widow & 14 (average number of children: 2) \\
Single & 6 \\
With children & 2 \\
Disease status & 6 \\
Clinically affected (After & \\
diagnostic testing) & \\
Non-carrier & \\
50\% risk & \\
25\% risk & \\
No biological relative & \\
Spouse/partner & \\
Uncle/aunt & \\
Daughter-in-law & \\
\hline
\end{tabular}

summaries were created, highlighting the most relevant aspects, contextual observations, and emerging ideas about topics to discuss in future interviews [26].

\section{Data analysis}

The transcribed interviews were analyzed thematically using coding and the method of constant comparison [26]. Each transcript and the corresponding interview notes were read repeatedly and the key topics addressed were mapped out. These were then coded, by breaking them down into small sections to identify the most significant items. Next, coded data were constantly compared within and among transcripts, to identify any likely connections. Recognized themes relating to non-engagement with PST were then grouped together in an iterative process, according to their main features and meaning. Findings were then interpreted with reference to a broad psychosocial framework aimed at understanding the interpersonal context that surrounds individuals and families, as they live with, or at risk for, an inherited disease [27-29].

\section{Results}

Each theme is presented (with data extracts) to illustrate key points. Quotations are accompanied by a code for the participants (consecutive lettering, to protect confidentiality), age and sex (F, female; M, male), as well as disease-related features. Content in square brackets is used to add intelligibility to the participant's quote; ellipsis with a single/ double dot means a brief/extended pause; underscored text indicates louder, more emphatic speech; “..." indicates some words or sentences were omitted; and " " indicates overlapping speech.

(1) Justifying the decision "not-to-know", because either no clinical benefit was expected or predictive knowledge was anticipated as psychologically burdensome

This theme was expressed in seven interviews and focuses on the reasons given by participants for remaining uninformed about their genetic status. In general, participants framed access to presymptomatic genetic information as being pointless, because no effective or acceptable treatment or palliation of symptoms was yet available for their family's disease:

I preferred to wait and see, because there is nothing one could do about it. If there were a treatment, a drug, something (.) I only did the analysis last year, because I started to feel my legs sort of tight (.) to lose balance and falling (.) I wanted to postpone it until I could not stand on my own any more. [A, 49 y, M, clinically affected (mild symptoms); two children]

Several participants framed engagement with genetic knowledge, although removing uncertainty, as having the potential to become seriously burdensome. Therefore, they preferred to live free from the psychological concerns posed by a pre-symptomatic diagnosis of an impending severe disease:

I rather not think about it, I really prefer not to know. I don't want to have that constantly popping up in my head (..) I prefer to deal with one thing at a time. $[B$, $30 \mathrm{y}, \mathrm{M}$, at $50 \%$ risk; $56 \mathrm{y}$ father severely affected]

Next, C describes how her decision not to undertake PST was also based on family members' experiences and reactions after knowing their results; by avoiding genetic testing and its potentially destabilizing knowledge, not only does she seek to preserve her own psychological wellbeing, but also that of her daughter: 
My sister decided to do the test and everything started to change: she sold her house and moved to a ground floor apartment, taking all decisions thinking that the future would come up badly and quick. It's just too frightening (.) I prefer to live the here and now (..) And I think: if I do it I'll start to obsess about it all the time, like 'I'll get it, I'll get it!' It happened to one of my cousins; she started to feel psychologically affected, you know (.) really down [...] And my daughter, she'd probably start to think she would have it as well and would miss the best years of her youth with this worry. $[C, 52 \mathrm{y}, \mathrm{F}, 50 \%$ risk; one daughter]

(2) Prioritizing everyday life, maintaining hope and the goal of living a normal life

This theme was widely shared among participants and shows how they articulated lifeworld considerations while discussing their options. Some participants anticipated that the potential worry regarding future health risks, following a "positive" test result, would impair their capacity to focus on their everyday life. Other participants claim the need to be psychologically "available" (i.e., free from the emotional unrest caused by a potentially adverse pre-symptomatic result) to assure caregiving for those affected, as well as parenting their children:

I don't think much about the disease (..) I really make an effort to avoid thinking about it. Now, I am very keen to be a father, you know (.) I just want to be a good father, it's my first [baby], I'm focused on that. $[B, 30 \mathrm{y}, \mathrm{M}$, at $50 \%$ risk; $56 \mathrm{y}$ father severely affected]

When asked if he would undertake PST if his (at-risk) mother had tested "positive", $D$ described his reasoning:

I guess I wouldn't, no. I'd see how it'd go (..) We just can't give up our lives! E [referring to his $59 \mathrm{y}$ uncle, severely affected, present at this family interview] is staying at a day-care facility (.) we need to stay united, and keep our jobs, so we can give him the best care we can; his brother, my other uncle, is staying at home because they can't afford the day-care centre, so they need to stay with him, to take care for him. It's like one step at a time. $[D, 41 \mathrm{y}, \mathrm{M}$, non-carrier; 2 children]

$F$ describes the case of his wife, who had not requested PST and has preferred to face the consequences of the disease only as they have arisen. In doing so, they framed this decision as an attempt to live in hope while they were a young couple:
She $[G$, wife] hasn't had the test as she rather wanted to live day by day ... and I think it was right, I agreed all along (.) One can't always be thinking about the worst, can we? When we got married ... people used to say "watch it, her mother has it and she [G] might have it too!'; but at that time you just want to move ahead, instead of not having a life, right? $[F, 54 \mathrm{y}, \mathrm{M}$, husband of $G, 48 \mathrm{y}, \mathrm{F}$, severely affected; no children]

(3) The wish to know: ambivalence and conflict within the family

Lastly, this theme describes considerations against deciding "not-to-know" and how it involved ambivalence and conflicting views within the family; it was addressed in about half of the interviews. Some participants described situations that would make them consider undertaking PST. These exceptions to their decision not-to-know were often framed for the sake of their children, as it could inform their reproductive decisions:

$C$ : "When she $[\mathrm{H}$, daughter] wants to have children, then I'll be happy to do the test, that's different. When another life is at stake you need to be sure. At that time, I didn't know anything about this, if I knew I would have done it".

$\sim H$ : Honestly, I don't think much about it. Of course, it's important to know what you can count on in the future, but I guess that's not a priority at this point in my life (.) Maybe when I decide I want to have a baby (..) It makes sense to be cautious: first to ask my mother to do the test, then to do it myself if needed, and then have the in vitro test [PGD]. [C, $52 \mathrm{y}, \mathrm{F}$, at $50 \%$ risk; one daughter, $H, 20 \mathrm{y}, \mathrm{F}$, at $25 \%$ risk]

There were instances, however, where some ambivalence and tension were noticeable in managing the way nonengagement with PST was perceived within the family, especially in relation to decisions about reproduction. The next excerpts are from a family interview:

I: My nephews (.) they're young, [they] are having children, they don't want to know... of course it's their life but that's (..) I don't think it's right (.) one thing is when you have children before you know it; but when you know and you run the risk of having a child with the disease, that's different.

$\sim D$ : This isn't like that, no, they deserve to be a whole family, to have a normal life! We can even be looked as being selfish, but they have the right to be 
parents, to give grandchildren to their parents, and so on, no matter what it may come to in the future. They deserve to have a family!

$E$ : They're doing right, they have time to know (..) what's the point of knowing when you're young anyway? (..) I've worked all my life (.) until I couldn't do it anymore (..) they shouldn't get stuck by that. $[I, 63 \mathrm{y}, \mathrm{F}$, non-carrier; three sons; $D, 41 \mathrm{y}, \mathrm{M}$, son of $I$, non-carrier; 2 children; $E, 59 \mathrm{y}, \mathrm{M}$, severely affected, brother of $I$; two sons]

There were also accounts that more explicitly showed criticism towards relatives' decisions not to undertake PST. These emphasize mainly the potential benefits of genetic knowledge to the planning of offspring's lives:

He [ex-partner, at 50\% risk for MJD] never wanted to know. I have been telling him he should do the test ever since, but he always preferred to avoid facing it (..) Now we're divorced, and I'd like to know whether my children might have it or not, it's a matter of organizing our life. He [looking at the older son, aged 11] already asks about it. I don't want to live hiding this from them. He understands what this is all about. You can only be prepared for something if you have the chance to know it in advance, right? [J, 35 y, F; two children at $25 \%$ risk]

\section{Discussion}

This is one of few studies exploring non-engagement with PST outside the usual cohorts seen in genetic counselling research. We report on individuals at-risk or affected by MJD about their decisions not to seek PST, therefore having remained uninformed about their genetic status. Accounts were made by participants about themselves or about family members, or made about them by other relatives. Decisions of non-engagement with PST were either reported as being the participant's current option or preferred option prior to becoming clinically affected. The main findings suggest that the value of genetic information is in the beholder and that (i) knowledge of genetic information is questioned when no effective treatment or cure is available; (ii) people have different tolerance thresholds for predictive information (and this impacts individuals within the family differently); (iii) the making of "responsible" decisions involves trading potential health risks, against a corresponding burden to present life, including its anticipated psychosocial impact; and (iv) tensions may arise between the best interest or wishes of a patient and those of other family members.

Participants were aware that PST could remove uncertainty as to whether they would be affected or not in the future; however, the incurable nature of MJD and lack of effective treatment, prompted most of these participants to perceive PST as being of little use. Under those circumstances, they also anticipated genetic knowledge as potentially burdensome. This is in line with research suggesting that participants tend to remain unengaged with predictive testing if it is perceived as too distressing [30]. Therefore, most participants acknowledged the possibility of undertaking a genetic (diagnostic) test in the future, only if or when they come to experience incipient symptoms. That was a preferred account for non-engagement with PST.

Decisions to remain uninformed about one's genetic status were also made to protect others in the family from this potentially destabilizing knowledge. As found in other studies, the assumption "to care not-to-know" was a compelling justification to avoid PST [31]. By deciding to avoid formal knowledge of their genetic status, these at-risk individuals seem not so much to actively reject PST, but rather choose to defer knowledge of their genetic status. This may represent an attempt to regain some sense of control over the impact that foreknowledge about their family's disease may have on their lives. In doing so, they seem to prioritize the focus of their lives on everyday pressing concerns (such as parenting their children or caregiving for affected relatives), without the destabilizing knowledge of an impending disease. Others prioritized keeping open the prospect of living a "valid", worthwhile life, as that allowed them to preserve hope towards the future. These reflections ultimately evidence the participants' personal and familial values, as to management of genetic risks [17, 21, 28, 29, 31-33].

Furthermore, our data provide accounts about other relatives' non-engagement with PST. While the accounts we elicited were generally supportive of those who chose not to know, differences were noticeable among family members regarding the value of information and implications towards others, especially pointing out reproductive decisions. Some participants described possible future events that might lead them to change their mind, as when their adult offspring would like to know their genetic status or are considering having children, so that the disease would not be passed down to the next generation. As such, those participants recognized some utility of their predictive genetic information, presenting themselves as responsible parents [31-33]; however, there was also criticism and blame, particularly directed towards at-risk relatives who had opted to pursue reproduction irrespective of the risk of transmitting the disease to offspring. This allocation of blame may represent a dominant moral consensus that sees 
engagement with genetic services as the morally sound way to conduct life in the presence of genetic risks [31-34].

The great majority of participants - at least overtly, on the surface - did not seem to regard non-engagement in genetics as something detrimental, irresponsible, or immoral. This is in contrast to previous studies focusing on other untreatable conditions [17, 18, 31-33]. In fact, some accounts framed the wish to protect family members from being actors of potentially blameworthy actions. While this may be explained by the unsettling emotional effects that may be promoted by divergent test results, this exonerates them from any charge of irresponsibility in the management of their lives and their genetic risks [34]. This suggests that the notion of genetic responsibility goes beyond the rational calculation of the use of genetic information and engagement with formal genetics knowledge and healthcare, extending to lifeworld goals and personal and family values.

\section{Implications for practice and future research perspectives}

Although the numbers are small, this study may contribute to highlight some aspects of the thinking of at-risk individuals and their family members, particularly how they negotiate decisions regarding PST and access to genetic knowledge. This may be relevant to the practice of genetic counselling and the provision of psychosocial support to families, by bringing further insights into the decisionmaking process of at-risk family members. Future research would benefit from collecting data from larger samples, including persons in a wide range of social and demographic circumstances and from diverse geographies, which may generate additional understanding of this topic. Styles of dealing with health risks vary with social and cultural values, and so does the influence played by genetic technology in shaping morality and decisions in regard to genetic disease [13, 14, 21, 22] and testing [35], and this certainly differs between regions and countries.

People's decisions and accounts may change once effective and acceptable therapies are available (or people think they are imminent). To what extent do the dynamics of hope for those at risk and their family members prompt changes in their mode of reasoning and decision-making in relation to genetic testing? How may a sense of empowerment and engagement with genetic healthcare best be promoted among at-risk individuals, while acknowledging their personal and collective experiences and decisions managing genetic risks and family relationships?

\section{Limitations of the study}

This study had a small data corpus and focused on Portuguese families with MJD, mostly living in the rural region of the Tagus valley (a high prevalence region) and its findings cannot be generalized. Therefore, conclusions may not apply to other populations or to other similar diseases. Also, we must consider that about one third of our participants did not complete high-school education, which may have impacted the findings. Finally, as participants were involved in snowball recruiting to the research, they may have invited to participate with them in an interview those family members with whom they anticipated less disagreement. They may also have felt somewhat inhibited in their statements due to the presence of other family members.

Acknowledgements We are grateful to all participants, and to Associação Portuguesa de Ataxias Hereditárias, for help with recruitment. We also thank Dr. Glória Matias for access to the facilities of the Chamusca's primary health centre for some of the interviews. We also wish to thank the reviewers for their valuable comments.

Funding ÁM undertook part of this work with the support of a postdoctoral fellowship from FCT - Fundação para a Ciência e Tecnologia (SFRH/BPD/88647/2012). Part of this work has been also financed by FEDER (COMPETE 2020 - POCI, Portugal 2020), and by FCT, in the framework of the project "Instituto de Investigação e Inovação em Saúde” (POCI-01-0145-FEDER-007274).

\section{Compliance with ethical standards}

Conflict of interest The authors declare that they have no conflict of interest.

\section{References}

1. Evers-Kiebooms G, Welkenhysen M, Claes E, Decruyenaere M, Denayer L. The psychological complexity of predictive testing for late onset neurogenetic diseases and hereditary cancers. Soc Sci Med. 2000;51:831-41.

2. Skirton H, Goldsmith L, Jackson L, Tibben A. Quality in genetic counselling for presymptomatic testing - clinical guidelines for practice across the range of genetic conditions. Eur J Hum Genet. $2013 ; 21: 256-60$

3. Sequeiros J, Coutinho P. Epidemiology and clinical aspects of Machado-Joseph disease. Adv Neurol. 1993;61:139-53.

4. Sequeiros J, Martins S, Silveira I. Epidemiology and population genetics of degenerative ataxias. In: Subramony S, Dürr A, editors. Ataxic Disorders: Handbook of Clinical Neurology. Elsevier: Amsterdam; 2012. pp. 227-51.

5. Coutinho P, Ruano L, Loureiro J, Cruz V, Barros J, Tuna A, et al. Hereditary ataxia and spastic paraplegia in Portugal: a populationbased prevalence study. JAMA Neurol. 2013;70:746-55.

6. Rodrigues C, Ziebell V, Camargo G, Osório C, de Castilhos R, Saraiva-Pereira M, et al. Presymptomatic testing for neurogenetic diseases in Brazil: assessing who seeks and who follows through with testing. J Genet Couns. 2012;21:101-12.

7. Baig S, Strong M, Rosser E, Taverner N, Glew R, Miedzybrodzka Z, et al. 22 years of predictive testing for Huntington's disease: the experience of the UK Huntington's Prediction Consortium. Eur J Hum Genet. 2016;24:1396-402.

8. Cruz-Mariño T, Velázquez-Pérez L, González-Zaldivar Y, Aguilera-Rodríguez R, Velázquez-Santos M, Vázquez-Mojena Y, 
et al. The Cuban program for predictive testing of SCA2: 11 years and 768 individuals to learn from. Clin Genet. 2013;83:518-24.

9. Gonzalez C, Gomes E, Kazachkova N, Bettencourt C, Raposo M, Kay $\mathrm{T}$, et al. Psychological well-being and family satisfaction levels five years after being confirmed as a carrier of the MachadoJoseph disease mutation. Genet Test Mol Biomarkers. 2012;16:1363-8.

10. Leite Â, Dinis M, Sequeiros J, Paúl C. Subjects at-risk for genetic diseases in Portugal: illness representations. J Genet Couns. 2016;25:79-89.

11. Lêdo S, Ramires A, Leite Â, Dinis M, Sequeiros, J. Long-term predictors for psychological outcome of pre-symptomatic testing for late-onset neurological diseases. Eur J Med Genet. 2018;61:575-80.

12. Rolim L, Leite Â, Lêdo S, Paneque M, Sequeiros J, Fleming M. Psychological aspects of pre-symptomatic testing for MachadoJoseph disease and familial amyloid polyneuropathy type I. Clin Genet. 2006;69:297-305.

13. Boutté $\mathrm{M}$. The stumbling disease: a case study of stigma among Azorean-Portuguese. Soc Sci Med. 1987;24:209-17.

14. Paúl C, Martin I, do Rosário M, Silva M, Coutinho P, Sequeiros J. Living with Machado-Joseph disease in a small rural community of the Tagus valley. Community Genet. 1999;2:190-5.

15. Decruyenaere M, Evers-Kiebooms G, Boogaerts A, Cloostermans T, Cassiman J, Demyttenaere K, et al. Non-participation in predictive testing for Huntington's disease: individual decisionmaking, personality and avoidant behaviour in the family. Eur $\mathbf{J}$ Hum Genet. 1997;5:351-63.

16. Binedell J, Soldan J, Harper P. Predictive testing for Huntington's disease: II. qualitative findings from a study of uptake in South Wales. Clin Genet. 1998;54:489-96.

17. Aureliano W. Health and the value of inheritance: the meanings surrounding a rare genetic disease. Vibrant. 2015;12:109-40.

18. Huniche L. Moral landscapes and everyday life in families with Huntington's disease: aligning ethnographic description and bioethics. Soc Sci Med. 2011;72:1810-6.

19. Callon M, Rabeharisoa V. Gino's lesson on humanity: genetics, mutual entanglements and the sociologist's role. Econ Soc. 2004;33:1-27.

20. Cowley L. What can we learn from patients' ethical thinking about the right 'not to know' in genomics? Lessons from cancer genetic testing for genetic counselling. Bioethics. 2016;30: $628-35$.
21. Keogh L, Niven H, Rutstein A, Flander L, Gaff C, Jenkins M. Choosing not to undergo predictive genetic testing for hereditary colorectal cancer syndromes: expanding our understanding of decliners and declining. J Behav Med. 2017;40:583-94.

22. Mendes Á, Sousa L, Sequeiros J, Clarke A. Discreditable legacy: stigma and familial amyloid polyneuropathy in north-western Portugal. Soc Sci Med. 2017;182:73-80.

23. Mendes Á, Metcalfe A, Paneque M, Sousa L, Clarke A, Sequeiros J. Communication of information about genetic risks: putting families at the center. Fam Process. 2018;57:836-46.

24. Oliveira C, Mendes Á, Sousa L. From older to younger: intergenerational promotion of health behaviours in Portuguese families with familial amyloid polyneuropathy. Eur J Hum Genet. 2017;25:687-93.

25. Silverman D. Doing qualitative research: a practical handbook. London: Sage Publications; 2005.

26. Strauss A, Corbin J. Basic of qualitative research: techniques and procedures for developing grounded theory. London: Sage Publications; 1998.

27. Arribas-Ayllon M, Sarangi S, Clarke A. Genetic testing: accounts of autonomy, responsibility and blame. London: Routledge; 2011.

28. Featherstone K, Atkinson P, Bharadwaj A, Clarke A. Risky relations: family, kinship and the new genetics. Berg: Oxford; 2006.

29. Atkinson P, Featherstone K, Gregory M. Kinscapes, genescapes \& timescapes: families living with genetic risk. Sociol Health Illn. 2013;35:1227-41.

30. McAllister M. Predictive genetic testing and beyond: a theory of engagement. J Health Psychol. 2002;7:491-508.

31. Konrad M. Narrating the new predictive genetics: ethics, ethnography and science. Cambridge: University Press; 2005.

32. Beeson D, Doksum T. Family values and resistance to genetic testing. In: Hoffmaster B, editors. Bioethics in social context. Philadelphia: Temple University Press; 2001. pp. 153-79.

33. Etchegary H, Fowler K. 'They had the right to know': genetic risk and perceptions of responsibility. Psychol Health. 2008;23: 707-27.

34. Arribas-Ayllon M, Sarangi S, Clarke A. Managing selfresponsibility through other-oriented blame: family accounts of genetic testing. Soc Sci Med. 2008;6:1521-32.

35. Parthasarathy S. Architecture of genetic medicine: comparing genetic testing for breast cancer in the USA and the UK. Soc Stud Sci. 2005;35:5-40. 